\title{
Odontostomatological therapeutic possibilities in patients with sleep apnea
}

\author{
José-María Martínez-González ${ }^{1}$, Natalia Martínez-Rodríguez ${ }^{2}$, Oscar Arias-Irimia ${ }^{3}$, María Martín-Ares ${ }^{2}$, \\ Cristina Barona-Dorado ${ }^{4}$
}

${ }^{1}$ Full Professor of Maxillofacial Surgery at Complutense University of Madrid and Head of the Department of Oral Facial and Implant Surgery at the University Hospital of Madrid

${ }^{2}$ Collaborator in the Department of Oral Facial and Implant Surgery at the University Hospital of Madrid

${ }^{3}$ Oral surgeon in the Department of Oral Facial and Implant Surgery at the University Hospital in Madrid

${ }^{4}$ Associate Professor of Oral Surgery at Complutense University of Madrid and Assistant Director of the Masters program in Oral Facial and Implant Surgery at University Hospital of Madrid

Correspondence:

Universidad Complutense de Madrid

Facultad de Odontología

Pza. Ramón y Cajal $s / n$

28040 Madrid, Spain

jmargo@odon.ucm.es

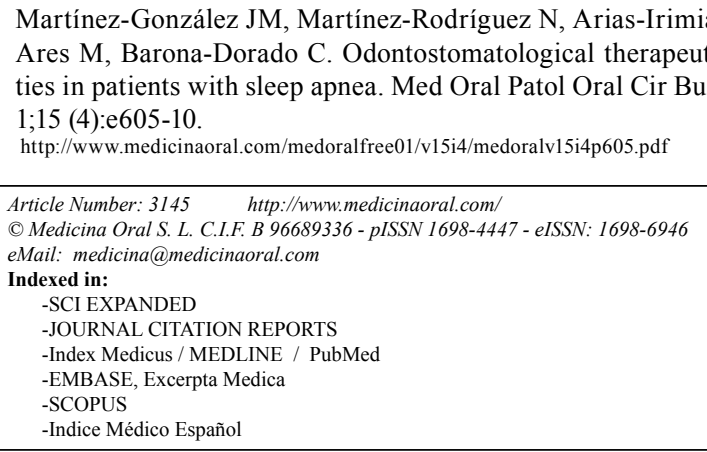

\begin{abstract}
Objectives: To evaluate the different therapeutic possibilities for treating Sleep Apnea/ Hypoapnea Syndrome (SAHS), as well as the effectiveness of such treatments, and to evaluate the epidemiological and clinical aspects of this syndrome.

Study design: We carried out a meta-analytical, observational and retrospective study by selecting a total of 13 articles, which provided a sample size of 642 diagnosed cases of SAHS.

Results: SAHS was more prevalent among males (88.7\%) and the average age of diagnosis was 49.75 years old. In the majority of cases, these patients were found to be overweight, with an average body mass index of $28.32 \mathrm{Kg} /$ $\mathrm{m}^{2}$. The average apnea / hypoapnea index was 31.64 apneas / hypoapneas per hour, which is therefore considered to be a moderate type of SAHS. The therapeutic approach involved intraoral mandibular advancement devices in $77.96 \%$ of the cases, followed by $16 \%$ of the patients who were treated with continuous positive airway pressure devices during sleep (CPAP), and lastly, 7\% underwent surgical treatment.

Conclusions: SAHS is a complex clinical condition that requires a multidisciplinary team in order to diagnose and treat it. There are several therapeutic possibilities available to professionals, which have obtained highly satisfactory results.
\end{abstract}

Key words: Sleep apnea syndrome, obesity, intraoral mandibular advancement devices, orthognathic surgery. 


\section{Introduction}

Obstructive sleep apnea syndrome (OSAS) is a hidden and potentially deadly sleep disorder in which there is a high incidence, and it is a very important public health issue as well as a social issue.

OSAS is characterized by a periodic collapse of the upper airways while sleeping, mainly during the REM phase, which causes an absence (apnea) or decrease (hypoapnea) of the airflow in the lungs despite the patient's persistent respiratory effort.

The prevalence of OSAS in western countries affects approximately $5 \%$ of adults, ranging from 3 to $10 \%$ of the male population in Spain, compared to $2 \%$ of the female population (1).

An adequate clinical history and an exhaustive physical exam will enable identifying patients who suffer OSAS. Polysomnography is used as the primary method for diagnosing SAHS, and is often used in conjunction with a lateral teleradiography of the head followed by a cephalometric study, which is a good indicator for defining and identifying where the obstruction is and even for helping to decide the therapeutic course of treatment to follow (1-4).

The apnea-hypoapnea index (AHI) is used by many professionals for confirming the diagnosis and quantifying the severity of the sleep disorder. The AHI is calculated by adding up the number of apneas (breathing interruptions lasting 10 seconds of more) and hypoapneas (the decrease, but not the complete interruption of the air flow which causes a 3\% drop in oxygen saturation or sleep disturbances) during the study, divided by the number of hours slept (1-5).

As for treatment, first, one must take a series of general steps towards losing weight, getting rid of habits such as using alcohol, tobacco or maintaining an irregular schedule, and must decrease the use of hypnotic or sedative drugs. Medical treatment consists of the CPAP, which is based on a high pressure device that releases an intense and continuous flow of air through a nose mask that the patient must wear while sleeping. In the dental treatment, there are a number of intraoral devices which, according to their mechanism of action, can be classified as: tongue retaining device (TRD), adjustable soft palate lifter (ASPL) and repositioning of the uvula, and mandibular advancement devices (MAD). The surgical alternatives vary greatly and range from a tracheostomy, surgery of the nasal passages, uvulopalatopharyngoplasty, surgery on the geniohyoid complex, glossectomy, and orthognathic surgery.

The objectives of our study are to evaluate the different therapeutic possibilities for treating OSAS as well as the effectiveness of these treatments, and to evaluate the clinical and epidemiological aspects of this syndrome.

\section{Material and Methods}

A meta-analytical, observational and retrospective study was carried out based on the results obtained from a bibliographic search in PubMed. The key words used were: "Sleep apnea syndrome", "obesity", "cephalometric analysis", and "positive pressure ventilation". We reviewed a total of 30 articles, ranging from the year 1996 to 2009, which had to meet the following established criteria in order to be included: articles that present more than 10 clinical cases of OSAS diagnosed by polysomnigraphy and/or cephalometric study, and that evaluate both the treatment used as well as its effectiveness.

The 13 articles selected provided a sample size of 642 cases, which were treated using descriptive statistics to evaluate the following parameters (Table 1):

Age: The age of the subjects was recorded at the time of the diagnosis.

Sex: The sex of the patient was recorded and a comparison between the occurrences of this disorder with respect to gender was also evaluated.

Type of OSAS: The subjects were categorized into groups and the frequency of occurrence was evaluated in each group, comparing it with the apnea/ hypoapnea index. Apnea/ Hypoapnea Index (AHI): The average of all of the subjects was recorded as well as their ranges, and then compared with the type of apnea.

Body Mass Index (BMI): The average for all of the patients was obtained, as well as the ranges, and the degree of obesity was compared with the type of OSAS. Treatment: The most common therapeutic approach used for the different patients as well as the effectiveness of such treatment was analyzed.

\section{Results}

The results of the population studied was variable according to each parameter indicated, given that it was impossible to obtain all of the data on each one of the individuals, projecting the following results:

With respect to the age variable, there were 539 patients evaluated at the time of the diagnosis, ranging in age from 23 to 78 years old (a range of 55 years), with the average age of diagnosis being 49.74 years old.

As far as the patient's sex, the OSAS in the population studied was more prevalent among males, reporting 362 cases and accounting for $88.7 \%$ of the group, compared to $11.27 \%$ or 46 cases among females. The ratio was 7.86 males per female (Fig. 1).

As far as the type of OSAS, 391 patients were diagnosed with moderate OSAS, representing $45.7 \%$ of the group and making it the most prevalent type, which is consistent with the AHI as can be observed below. The severe type of OSAS comes in second place in terms of prevalence and accounts for $36.1 \%$ of the population studied; lastly, those who suffer a mild type represent $18.2 \%$ of the cases. 
Table 1. Effectiveness of the different treatments (Oral Mandibular Advancement Devices - OMAD, Continuous Positive Air Pressure - CPAP, Surgical Treatment - ST) depending on the apnea / hypoapnea index (AHI).

\begin{tabular}{|c|c|c|c|c|}
\hline AUTHOR & $\begin{array}{c}\text { No. of } \\
\text { CASES }\end{array}$ & AHI & TREATMENT & EFFECTIVENESS \\
\hline Cohen 1998 (4) & $\begin{array}{c}25 \\
\text { A: } 15 \\
\text { B: } 10\end{array}$ & $\begin{array}{l}\text { A: } 43.7 \\
B: 11.3\end{array}$ & OMAD & $\begin{array}{l}\text { A: } 90 \% \\
\text { B: } 60 \%\end{array}$ \\
\hline $\begin{array}{l}\text { Rose et al. } \\
2002 \text { (5) }\end{array}$ & 26 & 17.8 & OMAD & $81 \%$ \\
\hline $\begin{array}{c}\text { Tegelberg et al. } \\
2003(6)\end{array}$ & $\begin{array}{c}74 \\
\text { A: } 38 \\
\text { B: } 36 \\
\end{array}$ & $\begin{array}{l}\text { A: } 16.2 \pm 2.9 \\
\text { B: } 18.9 \pm 4.7\end{array}$ & $\begin{array}{l}\text { A: OMAD } \\
\text { B: OMAD }\end{array}$ & $\begin{array}{l}\text { A: } 79 \% \\
\text { B: } 73 \%\end{array}$ \\
\hline $\begin{array}{c}\text { Hoekema et al. } \\
2007 \text { (7) }\end{array}$ & $\begin{array}{c}103 \\
A: 52 \\
B: 51\end{array}$ & $\begin{array}{l}\text { A: } 40.8 \pm 28 \\
\text { B: } 38 \pm 29.8\end{array}$ & $\begin{array}{l}\text { A: CPAP. } \\
\text { B: OMAD }\end{array}$ & $\begin{array}{l}\text { A: } 86 \% \\
\text { B: } 79.6 \%\end{array}$ \\
\hline $\begin{array}{l}\text { Santos Junior } \\
\text { et al. } 2007(8)\end{array}$ & 10 & $12.38 \pm 4.40$ & ST & $70 \%$ \\
\hline Lye et al. 2008 (9) & 15 & 69.12 & ST & $86.7 \%$ \\
\hline $\begin{array}{l}\text { Hoekema et al. } \\
2008 \text { (10) }\end{array}$ & $\begin{array}{c}103 \\
A: 52 \\
B: 51 \\
\end{array}$ & $\begin{array}{l}\text { A: } 39.4 \pm 30.8 . \\
\text { B: } 40.3 \pm 27.6\end{array}$ & $\begin{array}{l}\text { A: OMAD } \\
\text { B: CPAP }\end{array}$ & $\begin{array}{l}\text { A: } 76.5 \% \\
\text { B: } 82.7 \%\end{array}$ \\
\hline $\begin{array}{c}\text { Gindre et al. } 2008 \\
\text { (11) }\end{array}$ & $\begin{array}{c}66 \\
A: 50 \\
B: 16 \\
\end{array}$ & $\begin{array}{l}\text { A: } 42 \pm 20 \\
\text { B: } 29 \pm 19\end{array}$ & OMAD & $70 \%$ \\
\hline $\begin{array}{c}\text { Bruno Carlo et al. } \\
2008(12)\end{array}$ & 20 & 35 & ST & $100 \%$ \\
\hline $\begin{array}{c}\text { Doff et al. } 2009 \\
\text { (13) }\end{array}$ & 52 & $35.8 \pm 27.5$ & OMAD & $81 \%$ \\
\hline $\begin{array}{c}\text { Aarab et al. } 2009 \\
\text { (14) }\end{array}$ & 17 & $21.6 \pm 11.1$ & OMAD & $70 \%$ \\
\hline $\begin{array}{c}\text { Campbell et al. } \\
2009(15)\end{array}$ & $\begin{array}{c}28 \\
A: 12 \\
B: 16 \\
\end{array}$ & $\begin{array}{l}\text { A: } 26.5 \pm 12 \\
\text { B: } 25.4 \pm 7.4\end{array}$ & OMAD & $71 \%$ \\
\hline $\begin{array}{l}\text { Ghazal et al. } \\
2009 \text { (16) }\end{array}$ & $\begin{array}{c}103 \\
\text { A: } 51 \\
\text { B: } 52\end{array}$ & $\begin{array}{l}\text { A: } 32 \pm 6 \\
\text { B: } 37 \pm 8\end{array}$ & OMAD & $\begin{array}{l}\text { A: } 51 \% \\
\text { B: } 79.2 \%\end{array}$ \\
\hline
\end{tabular}

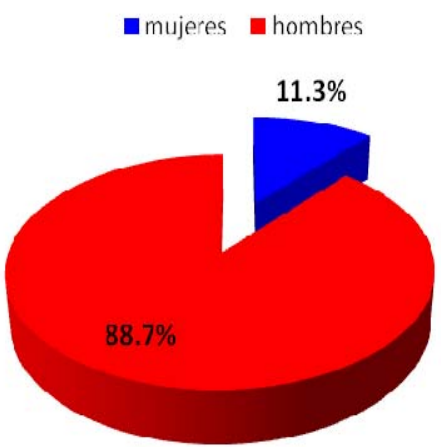

Fig. 1. Distribution by sex Mujeres: Females Hombres: Males
In this manner and consistent with that reported above, when recording the AHI, we obtained values that ranged dramatically: from 7.8 to 112 (a range of 104.2 apneashypoapneas per hour). The average value obtained in the 642 patients studied was 31.64 apneas-hypoapneas per hour, therefore constituting a moderate type of OSAS. As for the BMI, 494 patients presented a BMI between 26 and 68 at the time of being diagnosed, with a range of $42 \mathrm{Kg} / \mathrm{m}^{2}$ and the average value being $28.32 \mathrm{Kg} / \mathrm{m}^{2}$. Based on the classification used by the WHO, we were able to observe that the majority of the subjects were overweight. 


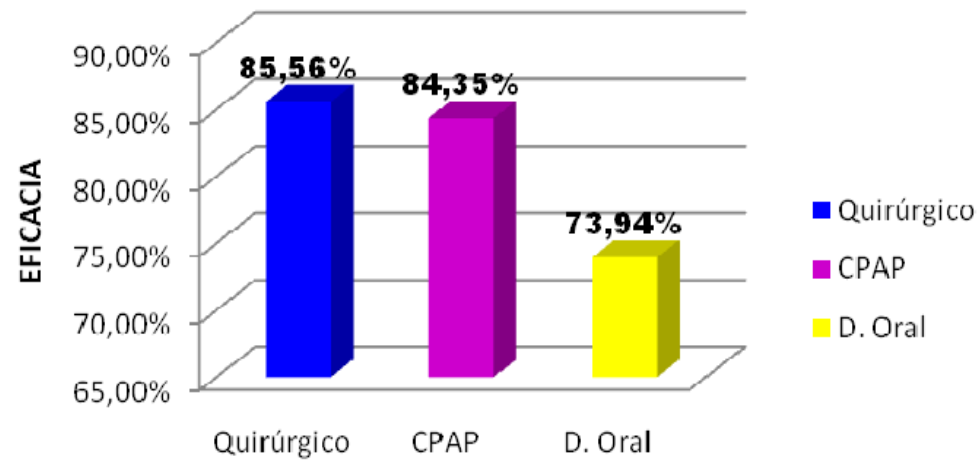

Fig. 2. Evaluation of the effectiveness according to surgical treatment, oral device and continuous positive air pressure (CPAP). Eficacia: Effectiveness Quirúrgico: Surgical treatment CPAP: Continuous positive air pressure D. Oral: Oral device

For $76.94 \%$ of the patients or in 494 cases, the most common therapeutic approach involved the use of intraoral devices designed to produce a mandibular advancement. A total of 103 subjects or $16 \%$ of the patients were treated with CPAP (continuous positive airway pressure devices during sleep), whereas 7\% (45 patients) underwent a mono or bimaxillary orthognathic surgery and/ or genioplasties. As for the effectiveness of the treatments, we were able to observe that the surgical treatment obtained an $85.56 \%$ success rate, followed by an $84.35 \%$ success rate in treatment using CPAP, whereas treatment with intraoral mandibular advancement devices were successful in $73.94 \%$ of the cases (Fig. 2).

\section{Discussion}

From a clinical perspective, OSAS is characterized by the triad of daytime fatigue (hypersomnia), snoring and pauses in breathing at night which is generally referred by the spouse or partner. These symptoms are simultaneously present in almost all those affected by this sleep disorder. In addition, other neuropsychiatric and cardiorespiratory disorders are common, which are secondary to the constant oxygen desaturations and to the temporary and subconscious sleep disturbances that are caused by the apneas (1).

As for the age of the patient when diagnosed with OSAS, authors such as Tegelberg et al. (6) consider the most common period to be between the fourth and fifth decades of life, an assertion that is consistent with our study in which the patients averaged 49.74 years of age when they were diagnosed. Despite this, authors such as Cohen (4) set a fairly large age range that usually goes from 23 to 78 years old.

As for the sex of the patient, there is a consensus among the authors consulted, supported by the fact that $88.7 \%$ of the subjects included in our study were male, compared to $11.3 \%$ who were female (7-16). There are various studies in which all of the patients were male, such as the case reported by Battagel et al. (3). Only the study by Van Haute et al. (17) contrasts the previous results, given that among their patients diagnosed with OSAS associated with metabolic disorders, particularly acromegaly, they estimate a slightly higher percentage (57.41\%) in females compared with males.

Clinically, OSAS can be divided into three categories described by the American Sleep Apnea Association, and are closely connected to the AHI; they are classified as: mild form when the AHI is between 5 and 20, moderate form if it is between 21 and 40, and severe form if it is more than 40 . Based on this classification, when evaluating the prevalence of each one of the clinical forms in our study, we found that the most common type is moderate OSAS, which accounts for $45.7 \%$ of the cases. In this respect, it is worth noting that in the study conducted by Bruno Carlo et al. (12), patients who had an average AHI of 35 apneas/ hypoapneas per hour were classified as having a severe OSAS, which is why based on the classification previously mentioned, we decided to group it with the moderate type.

As for the apnea/ hypoapnea index (AHI), both our study as well as the rest of the literature agrees that this variable is the one to be used for diagnosing OSAS, given that an AHI above 5 apneas/ hypoapneas per hour is considered to be pathological (1-3).

As for the body mass index (BMI), it should be noted that the majority of these patients present a problem associated with obesity, sometimes in combination with the use of alcohol and tobacco. In our case, all of the authors selected for our study presented subjects who 
were overweight according to the classification by the WHO, given that the average BMI was $28.32 \mathrm{Kg} / \mathrm{m}^{2}$. We can also infer that the type of OSAS is closely related to the degree of obesity, and that this plays a role when selecting the type of therapeutic procedure to be implemented. Along this same line, Lye et al. (9) present a group of 15 patients with a severe type of OSAS accompanied by an average BMI of $32.1 \mathrm{Kg} / \mathrm{m}^{2}$, which is a significant degree of obesity; after other treatments such as CPAP were unsuccessful, they opted for a more aggressive course of treatment, such as bimaxillary advancement orthognathic surgery.

The treatment of OSAS is considered multifactorial and must address several issues that need not be mutually exclusive. In the literature, there is a consensus on the need to first take a series of general steps in order to lose weight, get regular physical exercise, establish a schedule that enables a good sleep hygiene, and eliminate the use of alcohol and other hypnotic or sedative drugs. If we focus on more specific treatments, there is a wide variety of therapies, although none of them are completely satisfactory $(1,2)$.

As far as the effectiveness of the medical treatment, we obtained a success rate of $84.35 \%$ in our study. Nevertheless and despite this, other authors such as the case of Aarab et al. (14) or Rose et al. (5) report that there is a poor tolerance to the treatment over the long term given that it involves a chronic dependency of a machine that only produces a symptomatic improvement without curing the disorder. Along this same line, Gindre et al. (11) report similar findings in which the patients in the study had been previously treated with CPAP, obtaining poor results and a high rate of those who abandoned the treatment, finally opting for the mandibular advancement device.

In the odontological treatment, there are intraoral devices that have recently been gaining in popularity. The most frequently used are those designed to bring about a mandibular advancement that would enable an increase in the size of the air passages. The success obtained in our study was $73.94 \%$, not being exempt of secondary effects as affirmed by Campbell et al. (15), who point out hypersalivation, dryness of the mucosa and alterations of the TMJ in their patients. However, these results differ from those obtained by Jauhar et al. (18), given that it was only effective in $40 \%$ of the cases. Ghazal et al. (16) also evaluated the secondary effects at the dental level, concluding that the majority of the effects involve the incisors, and in $47.6 \%$ of the cases there was a significant reduction in the overbite.

The choice of surgical treatment versus other more conservative courses of treatment creates a certain dilemma given that there is no clear-cut response protocol for patients with this type of pathology. In our study, the techniques used were orthognathic surgery with mono or bimaxillary advancement, possibly combined with genioplasty, being the course of treatment that was most effective and obtained a success rate of $85.56 \%$. Similar results were reported by Foltán et al. (19) whose success rate was $74 \%$, using a technique that combines genioplasty with hyoid myotomy in patients with mild or moderate SAHS and with a BMI under $30 \mathrm{Kg} / \mathrm{m}^{2}$. A study conducted by Santos et al. (8) also reported similar results in which an effective rate of $70 \%$ was obtained when treating patients who were slightly overweight and had moderate sleep apnea. As far as orthognathic surgery, currently considered to be the optimum technique used in patients with severe SAOS, authors such as Thompson et al. (20) reported highly satisfactory results similar to ours.

Nevertheless, SAOS is a complex clinical condition that requires a multidisciplinary team for making the diagnosis as well as for treating it.

\section{References}

1. Rodríguez-Lozano FJ, Sáez-Yuguero Mdel R, Linares Tovar E, Bermejo Fenoll A. Sleep apnea and mandibular advancement device. Revision of the literature. Med Oral Patol Oral Cir Bucal. 2008;13:E549-54.

2. Friedlander AH, Friedlander IK, Pogrel MA. Dentistry's role in the diagnosis and co-management of patients with sleep apnoea/hypopnoea syndrome. Br Dent J. 2000;189:76-80.

3. Battagel JM, Johal A, Kotecha B. A cephalometric comparison of subjects with snoring and obstructive sleep apnoea. Eur J Orthod. 2000;22:353-65.

4. Cohen R. Obstructive sleep apnea: oral appliance therapy and severity of condition. Oral Surg Oral Med Oral Pathol Oral Radiol Endod. 1998;85:388-92.

5. Rose EC, Barthlen GM, Staats R, Jonas IE. Therapeutic efficacy of an oral appliance in the treatment of obstructive sleep apnea: a 2-year follow-up. Am J Orthod Dentofacial Orthop. 2002;121:273-9.

6. Tegelberg A, Walker-Engström ML, Vestling O, Wilhelmsson B. Two different degrees of mandibular advancement with a dental appliance in treatment of patients with mild to moderate obstructive sleep apnea. Acta Odontol Scand. 2003;61:356-62.

7. Hoekema A, Doff MH, de Bont LG, van der Hoeven JH, Wijkstra PJ, Pasma HR, et al. Predictors of obstructive sleep apnea-hypopnea treatment outcome. J Dent Res. 2007;86:1181-6.

8. Santos Junior JF, Abrahão M, Gregório LC, Zonato AI, Gumieiro EH. Genioplasty for genioglossus muscle advancement in patients with obstructive sleep apnea-hypopnea syndrome and mandibular retrognathia. Braz J Otorhinolaryngol. 2007;73:480-6.

9. Lye KW, Waite PD, Meara D, Wang D. Quality of life evaluation of maxillomandibular advancement surgery for treatment of obstructive sleep apnea. J Oral Maxillofac Surg. 2008;66:968-72.

10. Hoekema A, Stegenga B, Wijkstra PJ, van der Hoeven JH, Meinesz AF, de Bont LG. Obstructive sleep apnea therapy. J Dent Res. 2008;87:882-7.

11. Gindre L, Gagnadoux F, Meslier N, Gustin JM, Racineux JL. Mandibular advancement for obstructive sleep apnea: dose effect on apnea, long-term use and tolerance. Respiration. 2008;76:386-92.

12. Bruno Carlo B, Mauro P, Silvia B, Enrico S. Modified genioplasty and bimaxillary advancement for treating obstructive sleep apnea syndrome. J Oral Maxillofac Surg. 2008;66:1971-4.

13. Doff MH, Hoekema A, Pruim GJ, van der Hoeven JH, de Bont LG, Stegenga B. Effects of a mandibular advancement device on the upper airway morphology: a cephalometric analysis. J Oral Rehabil. 2009;36:330-7.

14. Aarab G, Lobbezoo F, Hamburger HL, Naeije M. Effects of an 
oral appliance with different mandibular protrusion positions at a constant vertical dimension on obstructive sleep apnea. Clin Oral Investig. 2010;14:339-45.

15. Campbell AJ, Reynolds G, Trengrove H, Neill AM. Mandibular advancement splint titration in obstructive sleep apnoea. Sleep Breath. 2009;13:157-62.

16. Ghazal A, Sorichter S, Jonas I, Rose EC. A randomized prospective long-term study of two oral appliances for sleep apnoea treatment. J Sleep Res. 2009;18:321-8.

17. Van Haute FR, Taboada GF, Corrêa LL, Lima GA, Fontes R, Riello AP, et al. Prevalence of sleep apnea and metabolic abnormalities in patients with acromegaly and analysis of cephalometric parameters by magnetic resonance imaging. Eur J Endocrinol. 2008;158:459-65. 18. Jauhar S, Lyons MF, Banham SW, Orchardson R, Livingston E. The attitudes of general dental practitioners and medical specialists to the provision of intra-oral appliances for the management of snoring and sleep apnoea. Br Dent J. 2008;205:653-7; dicussion 647.

19. Foltán R, Hoffmannová J, Pretl M, Donev F, Vlk M. Genioglossus advancement and hyoid myotomy in treating obstructive sleep apnoea syndrome - A follow-up study. J Craniomaxillofac Surg. 2007;35:246-51.

20. Thompson SH, Quinn M, Helman JI, Baur DA. Maxillomandibular distraction osteogenesis advancement for the treatment of obstructive sleep apnea. J Oral Maxillofac Surg. 2007;65:1427-9. 